\title{
Racial/Ethnic Disparities in Primary Care Quality Among Type 2 Diabetes Patients, Medical Expenditure Panel Survey, 2012
}

\author{
Ruwei Hu, PhD; Leiyu Shi, DrPH, MBA, MPA; Hailun Liang, MS; \\ Geraldine Pierre Haile, PhD; De-Chih Lee, PhD
}

\begin{abstract}
Suggested citation for this article: Hu R, Shi L, Liang H, Haile GP, Lee DC. Racial/Ethnic Disparities in Primary Care Quality Among Type 2 Diabetes Patients, Medical Expenditure Panel Survey, 2012. Prev Chronic Dis 2016;13:160113. DOI: http://dx.doi.org/10.5888/pcd13.160113.
\end{abstract}

\section{PEER REVIEWED}

\section{Abstract}

\section{Introduction}

Racial and ethnic disparities exist in diabetes prevalence, access to diabetes care, diabetes-related complications and mortality rates, and the quality of diabetes care among Americans. We explored racial and ethnic disparities in primary care quality among Americans with type 2 diabetes.

\section{Methods}

We analyzed data on adults with type 2 diabetes derived from the household component of the 2012 Medical Expenditure Panel Survey. Multiple regression and multivariate logistic regressions were used to examine the association between race/ethnicity and primary care attributes related to first contact, longitudinality, comprehensiveness, and coordination, and clusters of confounding factors were added sequentially.

\section{Results}

Preliminary findings indicated differences in primary care quality between racial/ethnic minorities and whites across measures of first contact, longitudinality, comprehensiveness, and coordination. After controlling for confounding factors, these differences were no longer apparent; all racial/ethnic categories showed similar rates of primary care quality according to the 4 primary care domains of interest in the study.

\section{Conclusion}

Results indicate equitable primary care quality for type 2 diabetes patients across 4 key domains of primary care after controlling for socioeconomic characteristics. Additional research is necessary to support these findings, particularly when considering smaller racial/ethnic groups and investigating outcomes related to diabetes.

\section{Introduction}

Approximately 29.1 million Americans have diabetes, and type 2 diabetes accounts for $90 \%$ to $95 \%$ of all diagnosed cases in adults (1). An estimated 1 in 4 people with diabetes are unaware of their condition (1). In 2010, diabetes was the seventh leading cause of death in the United States, and the total direct and indirect costs associated with the condition were an estimated \$245 billion (1). Even after adjusting for age and sex differences at the population level, average medical expenditures among people diagnosed with diabetes were 2.3 times higher than among people without diabetes (1).

Decades of literature have found racial and ethnic disparities in the prevalence of diabetes, access to diabetes care, diabetes-related complications and mortality rates, and the quality of diabetes care (2). More specifically, the risk of diabetes was $77 \%$ higher among African Americans and 66\% higher among Hispanic/Latino Americans than among non-Hispanic white Americans (3). NonHispanic black patients with diabetes were significantly less likely to receive low-density lipoprotein (LDL) cholesterol testing than were white patients who received care at the same facility (4). Black patients were also more likely than white patients to have poor blood pressure and cholesterol control $(4,5)$.

Although previous literature describes racial disparities in diabetes prevalence and treatment, little exploration has been conducted on the relationship between race and ethnicity and primary care quality among patients with diabetes. This is relevant, because primary care is effective in the management of diabetes 
(6-8). Assessments of the quality of primary care should consider the 4 cardinal dimensions: first contact, longitudinality, comprehensiveness, and coordination (9). First contact care refers to care first sought from the primary care provider when a new health or medical need arises. Longitudinality refers to the longitudinal use of a regular source of care over time, regardless of the presence or absence of disease or injury. Comprehensiveness refers to the availability of a range of services in primary care and their provision by a primary care provider across the spectrum of needs for all but the most uncommon problems in the population. Coordination is the linking of health care visits and services so that patients receive appropriate care for all their health problems, physical as well as mental (10).

It was difficult to draw firm conclusions from the literature about racial/ethnic differences in primary care quality among type 2 diabetes patients (11-14). For example, results from a study conducted by Brown et al found that being from a racial/ethnic minority group was not consistently associated with worse processes or outcomes in quality of diabetes care, and not all differences favored white patients (11). Results from another study by Murray-García et al suggested that Asian and Latino patients were less satisfied with primary care than were white patients (12). In addition, many previous studies included only clinical measures - such as hemoglobin A1c, LDL cholesterol level, and plasma glucose - as their research outcomes of interest $(11,13-15)$. Other studies on patients' ratings of quality of care included samples only from a specific geographic area or setting (eg, using state and health systems data) $(11,12)$.

To our knowledge, little nationwide and updated research exists that focuses on the racial/ethnic disparities in primary care quality among type 2 diabetes patients. The purpose of our study was to explore racial/ethnic disparities in primary care quality - particularly, the domains of first contact, longitudinality, comprehensiveness, and coordination - among Americans with type 2 diabetes.

\section{Methods}

We used data from the household component of the 2012 Medical Expenditure Panel Survey (MEPS), which was the latest publicly accessible data set at the time of our study. MEPS is a nationally representative survey of the US noninstitutionalized civilian population, comprising survey data of families and individuals and their medical providers and employers. MEPS is supported by the Agency for Healthcare Research and Quality (16). The 2012 MEPS contained 38,974 observations; our study included respondents aged 18 or older who reported being told by a clinician that they had type 2 diabetes. We excluded respondents who had missing values for race/ethnicity. A total of 2,617 people with type 2 diabetes were included in the study, representing an estimated $21,813,781$ adults with self-reported diabetes. The final sample and population size for each dependent variable varied because of missing or inapplicable values for different dependent measures.

\section{Measures}

The household component of MEPS collects detailed data on demographic characteristics, health conditions, health status, use of medical care services, charges and payments, access to primary care, satisfaction with care, health insurance coverage, annual income, and employment. In this study, measures of primary care attributes (dependent variables), race/ethnicity (independent variable), and individual characteristics (covariates) were used.

According to previous work conducted on primary care (17-19), we considered 4 cardinal domains of primary care - first contact, longitudinality, comprehensiveness, and coordination - in looking at primary care attributes as dependent variables of interest in the analyses. Eight questions were selected from MEPS pertaining to first contact and were coded. First contact characteristics were have a usual source of care (USC) (yes $=1$, no $=0$ ), because research has used "has a USC" as a structural component of the health care system that appropriately reflects an individual's entry into the system (12); provider type of USC (facility $=0$, person/ person in facility $=1$ ); provider specialty of USC (primary care $=$ 1 , other $=0$ ); USC location (office $=1$, hospital $=0$ ); difficulty contacting USC by telephone (not very difficult $=1$, very difficult $=0$ ); USC has office hours on nights/weekends (yes $=1$, no $=0$ ); time to get to USC $(\leq 30 \mathrm{~min}=1,>30 \mathrm{~min}=0)$; and difficulty in getting to USC (not difficult $=1$, difficult $=0$ ). Longitudinality was assessed with 1 question: "Does the USC provider listen?" (yes $=1$, no $=0$ ). Comprehensiveness was assessed with 1 question: "Does the patient go to a USC for preventive health care?" (yes $=1$, no $=0$ ). Coordination was assessed with 2 questions: "Does the provider ask about other treatments?" $($ yes $=1$, no $=0)$ and "Does the patient go to a USC for referrals?" (yes $=1$, no $=0$ ).

Andersen and Aday's access-to-care framework, among the most well-known and widely used models for demonstrating the factors that lead to the use of health care services, was used in the selection of individual covariates that may be related to the experience of primary care (20). According to this framework, health care use is influenced by predisposing, enabling, and need factors. Predisposing factors refers to exogenous factors - such as age, sex, race/ethnicity, and other social structure and health belief factors - that affect one's inclination to use health care services. Enabling factors are the ability of an individual to access care and the availability of services. Need factors take into account factors such as health status, existing diseases, and other chronic conditions (20). On the basis of these components of the framework, we ex-

\footnotetext{
The opinions expressed by authors contributing to this journal do not necessarily reflect the opinions of the U.S. Department of Health and Human Services, the Public Health Service, the Centers for Disease Control and Prevention, or the authors' affiliated institutions.
} 
tracted covariate measures for the study. Predisposing characteristics were age (18-45 y, 46-64 y, >64 y); sex (male, female); race/ ethnicity (non-Hispanic white, non-Hispanic black, Hispanic, nonHispanic Asian, non-Hispanic other); health insurance (public, private, no insurance); education (no degree, high school diploma, bachelor and higher degree, other); employment status (not employed, employed); annual income $(<\$ 20,000, \$ 20,000-\$ 39,999$, $\geq \$ 40,000$ ); and marital status (married, not married). Enabling factors included were metropolitan statistical area (MSA), a geographical region with a high population density at its core and close economic ties (yes, no); and census region (Northeast, Midwest, South, West). Need factors of interest were perceived health status (excellent/very good/good, fair/poor); perceived mental health status (excellent/very good/good, fair/poor); need help with activities of daily living (ADL help screener) (yes, no); and need help with instrumental activities of daily living (IADL help screener) (yes, no).

\section{Analysis}

Data analysis was performed using Stata/SE version 14.0 (StataCorp, LP), accounting for the multistage, stratified cluster sampling associated with MEPS. All analysis accounted for sampling weights. Bivariate comparisons were performed between an individual's race/ethnicity and primary care attributes. We used $\chi^{2}$ tests to determine whether there were differences among racial/ ethnic groups in primary care quality. We also constructed 4 scored summary variables representing each of the primary care domains. We first assigned scores to each of the questions and then created an integrated variable by summing the total scores of questions within each domain. Therefore, the score ranges for the 4 domains - first contact, longitudinality, comprehensiveness, and coordination - were 0 to 8,0 to 1,0 to 1 , and 0 to 2 , respectively. However, we recoded the coordination domain as dichotomous because of the distribution of total scores within the domain. We recoded the coordination domain score as 0 if the original score was 0 or 1 , and we recoded the domain score as 1 if the original score was 2. ANOVA was performed to determine whether there was significant difference among racial/ethnic groups in first contact quality. We used $\chi^{2}$ tests to determine whether there were differences among racial/ethnic groups in longitudinality, comprehensiveness, and coordination domains. Multiple regression and multivariate logistic regressions were used to examine the association between race/ethnicity and primary care attributes related to first contact, longitudinality, comprehensiveness, and coordination, by sequentially adding the clusters of confounding factors in the following order: predisposing factors, enabling factors, and need factors. In our regression models, we used the 4 integrated variables of 4 primary care domains rather than individual items and applied hierarchical modeling approach to investigate in great- er depth, so we could understand the contributors to disparities in primary care quality. Model 1 was unadjusted regressions. Model 2 was adjusted for predisposing factors. Model 3 was adjusted for predisposing and enabling factors. Model 4 was fully adjusted, accounting for predisposing, enabling, and need factors. We used standard errors, $P$ values, $\beta$ coefficients, odds ratios (ORs), and $95 \%$ confidence intervals (CIs) to interpret significance and effect size.

\section{Results}

In 2012, 21,813,781 American adults had type 2 diabetes. Most of those with the condition were aged 46 to 64 years $(43.8 \%) ; 42.8 \%$ were aged 65 or older. Adults with a high school diploma, the unemployed, and those with annual income below \$20,000 accounted for more than half of those with diabetes. The southern census region represented $41 \%$ of diabetes cases; urban areas accounted for $82 \%$ (Table 1).

When looking at primary care characteristics among the population with diabetes by race/ethnicity, $91 \%$ of non-Hispanic blacks, $86 \%$ of Hispanics, and $89 \%$ of non-Hispanic other racial/ethnic groups reported having a USC, compared with $94 \%$ of non-Hispanic whites and 94\% of non-Hispanic Asians $(P<.01)$ (Table 2$)$. Non-Hispanic blacks (49\%), Hispanics (60\%), and non-Hispanic others $(60 \%)$ were more likely to report a facility rather than a specific provider to be their USC than were white (40\%) and Asian adults $(38 \%)(P<.001)$; hospitals accounted for $25 \%$ of USC locations among non-Hispanic blacks, 43\% among Hispanics, 25\% among non-Hispanic others, and only $17 \%$ and $18 \%$ among nonHispanic whites and Asians, respectively $(P<.001)$. No significant differences were found in mean scores for first contact domain among the $5 \mathrm{racial} / \mathrm{ethnic}$ groups. Non-Hispanic others reported going to a USC for preventive health care at a lower rate $(96 \%)$ than did Hispanics and non-Hispanic white, black, and Asian adults, who all reported approximately $99 \%$ on this comprehensiveness item $(P<.05)$. A similar pattern emerged when looking at whether individuals sought care at a USC for referrals, where nonHispanic others reported $91 \%$, compared with $98 \%$ to $99 \%$ for the other racial/ethnic groups $(P<.01)$. The results for the recoded measure of evaluating the coordination domain were also significantly different among the $5 \mathrm{racial} /$ ethnic groups; $82 \%$ of non-Hispanic blacks, $83 \%$ of Hispanics, $74 \%$ of non-Hispanic Asians, and $69 \%$ of non-Hispanic others reported as having primary care coordination, compared with $83 \%$ of non-Hispanic whites $(P<.05)$ (Table 2).

Table 3 shows the results of cumulative effect of factors on racial/ ethnic differences in primary care characteristics for adults with type 2 diabetes at the population level. Model 1 shows the unad-

The opinions expressed by authors contributing to this journal do not necessarily reflect the opinions of the U.S. Department of Health and Human Services, the Public Health Service, the Centers for Disease Control and Prevention, or the authors' affiliated institutions. 
justed $\beta$ coefficient or OR for each primary care domain among each racial/ethnic minority group compared with whites. Similar to the finding of the first contact domain score in Table 2 - except for non-Hispanic Asians, who were more likely to rate higher $(\beta=0.264 ; 95 \% \mathrm{CI}, 0.075-0.453 ; P<.01)$ - no other significant associations were found among racial/ethnic groups and differences in the first contact scores. For longitudinality indicators, non-Hispanic blacks $(\mathrm{OR}=0.298 ; 95 \% \mathrm{CI}, 0.091-0.974 ; P<.05)$ and Hispanics $(\mathrm{OR}=0.203 ; 95 \% \mathrm{CI}, 0.066-0.627 ; P<.01)$ were less likely to report that their USC providers listened to them compared with non-Hispanic whites. With respect to comprehensiveness indicators, non-Hispanic others $(\mathrm{OR}=0.172 ; 95 \% \mathrm{CI}$, $0.033-0.905 ; P<.05)$ were less likely than whites to report that they went to their USC for preventive health care.

Models 2 through 4 show the results of multiple regressions or multivariate logistic regressions (Table 3 ). The $\beta$ coefficients or ORs were adjusted for covariates potentially related to the experience of primary care by sequentially adding the clusters of covariates in the following order: predisposing, enabling, and need factors. For the first contact domain, non-Hispanic Asians still had significantly higher scores $(\beta=0.258,95 \% \mathrm{CI}, 0.066-0.450, P<$ 0.01 ) after accounting for individuals' predisposing factors. For the first contact domain, adults aged 46 to 64 years were associated with significantly lower scores $(\beta=-0.187 ; 95 \% \mathrm{CI},-0.353$ to $-0.022 ; P<.05)$, adults with an annual income of $\$ 20,000$ to $\$ 39,999$ were associated with significantly higher scores $(\beta=$ $0.138 ; 95 \% \mathrm{CI}, 0.007-0.270 ; P<.05)$, and married adults $(\beta=$ $0.203 ; 95 \%$ CI, $0.098-0.308 ; P<.001)$ were associated with significantly higher scores. Similar results were also found in Models 3 and 4. Moreover, enabling factors such as MSA and census region were also significantly associated with differences in first contact scores; whereas need factors were not.

For the longitudinality domain, the significant differences that were found in Model 1 were no longer apparent in Model 2 after adjusting for predisposing factors, in Model 3 after adjusting for predisposing and enabling factors, and in the fully adjusted Model 4 after accounting for all predisposing, enabling, and need factors. Only one racial/ethnic minority group, Hispanics $(\mathrm{OR}=0.270$; $95 \%$ CI, $0.083-0.833 ; P<.05)$, was still significantly associated with lower odds in reporting that USC provider listened in Model 2 , and no negative associations were found in Models 3 and 4. The predisposing factors of being older than 64 years and female were associated with higher odds of reporting that providers listened to them. No enabling and need factors were associated with the longitudinality indicator.

For comprehensiveness domain, the significant association between non-Hispanic others and lower odds of going to a USC for preventive health care in Model 1 were no longer significant after controlling for the confounding factors in Models 2 through 4. For the coordination domain, no significant associations between racial/ethnic groups and lower odds of a provider asking about other treatments were found after adding the clusters of predisposing, enabling, and need factors. The predisposing factors of being uninsured and being at the $\$ 20,000$ to $\$ 39,999$ income level, and the enabling factors of MSA area and being in the Midwest and West census region were associated with lower odds of the provider asking about other treatments.

\section{Discussion}

Although early differences in quality of care existed when exploring racial and ethnic disparities in primary care for patients with type 2 diabetes, these differences were no longer significant after controlling for confounding factors. Other predisposing and enabling factors, such as age, annual income, marital status, insurance coverage, MSA and census region, were associated with differences in certain primary care quality domains. This finding is consistent with findings of previous research, which indicate that socioeconomic status (SES) is a stronger determinant of diabetes status and outcomes than is race/ethnicity $(2,21,22)$.

Beginning with Healthy People 2000, efforts to eliminate racial/ ethnic disparities have been on the US national health policy agenda $(23,24)$. A growing body of targeted programs, initiatives, and studies have been implemented to improve quality and address disparities in health care for racial/ethnic minorities (25). Previous evidence indicates the crucial role that primary care plays in the quality and accessibility of care for patients (26). Our research showed that when variables related to SES are controlled for, racial and ethnic disparities in access to and quality of primary care among diabetes patients were reduced and disappeared. Policy makers should continue their commitment to extend primary care to patients and focus on patients with lower SES in an effort to provide equitable services to all.

When looking at differences by race/ethnicity, patterns for nonHispanic others often mirrored those of Hispanics and non-Hispanic blacks, with primary care quality being lower for these adults than for non-Hispanic white and Asian adults. Additional research should be conducted on the composition of the "other" racial/ethnic category to draw more precise conclusions about the primary care needs of this diverse population.

Our study has limitations. First, MEPS data on primary care are self-reported and are subject to recall bias. Second, the secondary nature of the data set precluded causal inferences. Third, the study investigated the primary care experience reported by the patients rather than their health outcomes. More studies are needed to examine the associations between the process and outcome of

\footnotetext{
The opinions expressed by authors contributing to this journal do not necessarily reflect the opinions of the U.S. Department of Health and Human Services, the Public Health Service, the Centers for Disease Control and Prevention, or the authors' affiliated institutions.
} 
primary care among minority patients with diabetes. Finally, our measures of primary care attributes were operationalized from MEPS rather than being researcher-initiated measures, which limited the ability to include all the major measures of primary care, especially for measures of longitudinality and comprehensiveness (7). Other measures could be selected from MEPS to investigate the effects of the 4 domains in varying ways.

Despite these limitations, this study presents relevant findings to the field and could improve the care provided to patients with diabetes. Our findings indicate that primary care quality is equitable for diabetes patients across 4 key domains of primary care. In addition to racial/ethnic disparities in health and health care, other socioeconomic stratification factors, such as minorities disproportionately having low income and vulnerable populations having higher risk of being chronically ill and disabled, may be the cause of these disparities in population health (27). Federal efforts targeted at eliminating racial/ethnic disparities in health and health care are long-standing and persistent (28). The Patient Protection and Affordable Care Act brought provisions related broadly to health insurance coverage, which would reduce SES-related disparities in insurance coverage and access to care (28). Future efforts are needed to investigate both race-based and SES-based disparities in population health and health care. Most of the evidence suggests that equitable primary care eliminates disparities $(19,29,30)$. Next steps and future research should be undertaken to examine the role of primary care in improvements in the management of chronic diseases by reducing both race-based and SESbased disparities.

\section{Acknowledgments}

The study was sponsored by the Johns Hopkins Primary Care Policy Center. The authors have no additional financial disclosures or conflicts of interest.

\section{Author Information}

Corresponding Author: De-Chih Lee, PhD, Associate Professor, Department of Information Management, Da-Yeh University, Dacun, Changhua 51591, Taiwan, R.O.C. Telephone: 886-4-8511888. Email: declee@mail.dyu.edu.tw.

Author Affiliations: Ruwei Hu, Department of Health Management, School of Public Health, Sun Yat-sen University, China, and Johns Hopkins Primary Care Policy Center, Baltimore, Maryland; Leiyu Shi, Johns Hopkins Primary Care Policy Center, Johns Hopkins Bloomberg School of Public Health, Baltimore, Maryland; Hailun Liang, Johns Hopkins Primary Care Policy Center, Baltimore, Maryland; Geraldine Pierre Haile, Johns
Hopkins Primary Care Policy Center, Baltimore, Maryland, and Mathematica Policy Research, Oakland, California. Dr Lee is also affiliated with the Johns Hopkins Primary Care Policy Center, Baltimore, Maryland, and Da-Yeh University, Taiwan.

\section{References}

1. Centers for Disease Control and Prevention. National diabetes statistics report: estimates of diabetes and its burden in the United States, 2014. http://www.cdc.gov/diabetes/pubs/ statsreport14/national-diabetes-report-web.pdf. Accessed March 11, 2016.

2. Beach MC, Gary TL, Price EG, Robinson K, Gozu A, Palacio $\mathrm{A}$, et al. Improving health care quality for racial/ethnic minorities: a systematic review of the best evidence regarding provider and organization interventions. BMC Public Health 2006;6(1):104.

3. Chow EA, Foster H, Gonzalez V, McIver L. The disparate impact of diabetes on racial/ethnic minority populations. Clin Diabetes 2012;30(3):130-3.

4. Heisler M, Smith DM, Hayward RA, Krein SL, Kerr EA. Racial disparities in diabetes care processes, outcomes, and treatment intensity. Med Care 2003;41(11):1221-32.

5. Kirk JK, D’Agostino RB Jr, Bell RA, Passmore LV, Bonds DE, Karter AJ, et al. Disparities in HbAlc levels between African-American and non-Hispanic white adults with diabetes: a meta-analysis. Diabetes Care 2006;29(9):2130-6.

6. Couch C, Sheffield P, Gerthoffer T, Ries A, Hollander P. Clinical outcomes in patients with type 2 diabetes managed by a diabetes resource nurse in a primary care practice. Proc (Bayl Univ Med Cent) 2003;16(3):336-40.

7. Morrison F, Shubina M, Goldberg SI, Turchin A. Performance of primary care physicians and other providers on key process measures in the treatment of diabetes. Diabetes Care 2013; 36(5):1147-52.

8. Renders CM, Valk GD, Griffin SJ, Wagner EH, Eijk Van JT, Assendelft WJ. Interventions to improve the management of diabetes in primary care, outpatient, and community settings: a systematic review. Diabetes Care 2001;24(10):1821-33.

9. Shi L. Type of health insurance and the quality of primary care experience. Am J Public Health 2000;90(12):1848-55.

10. Shi L, Starfield B, Xu J. Validating the adult Primary Care Assessment Tool. J Fam Pract 2001;50(2):161-75.

11. Brown AF, Gregg EW, Stevens MR, Karter AJ, Weinberger M, Safford MM, et al. Race, ethnicity, socioeconomic position, and quality of care for adults with diabetes enrolled in managed care: the Translating Research Into Action for Diabetes (TRIAD) study. Diabetes Care 2005;28(12):2864-70.

The opinions expressed by authors contributing to this journal do not necessarily reflect the opinions of the U.S. Department of Health and Human Services, the Public Health Service, the Centers for Disease Control and Prevention, or the authors' affiliated institutions. 
12. Murray-García JL, Selby JV, Schmittdiel J, Grumbach K, Quesenberry CP Jr. Racial and ethnic differences in a patient survey: patients' values, ratings, and reports regarding physician primary care performance in a large health maintenance organization. Med Care 2000;38(3):300-10.

13. Sequist TD, Adams A, Zhang F, Ross-Degnan D, Ayanian JZ. Effect of quality improvement on racial disparities in diabetes care. Arch Intern Med 2006;166(6):675-81.

14. Herman WH, Dungan KM, Wolffenbuttel BH, Buse JB, Fahrbach JL, Jiang H, et al. Racial and ethnic differences in mean plasma glucose, hemoglobin A1c, and 1,5anhydroglucitol in over 2000 patients with type 2 diabetes. J Clin Endocrinol Metab 2009;94(5):1689-94.

15. Herman WH, Ma Y, Uwaifo G, Haffner S, Kahn SE, Horton $\mathrm{ES}$, et al. Differences in $\mathrm{A} 1 \mathrm{C}$ by race and ethnicity among patients with impaired glucose tolerance in the Diabetes Prevention Program. Diabetes Care 2007;30(10):2453-7.

16. Agency for Healthcare Research and Quality. Medical Expenditure Panel Survey. http://meps.ahrq.gov/mepsweb/. Accessed March 11, 2016.

17. Starfield B. Primary care: concept, evaluation, and policy. New York (NY): Oxford University Press; 1992.

18. Starfield B. Primary care: balancing health needs, services and technology. Oxford (UK): Oxford University Press; 1998.

19. Shi L. The impact of primary care: a focused review. Scientifica (Cairo) 2012;2012:432892.

20. Andersen R, Aday LA. Access to medical care in the U.S.: realized and potential. Med Care 1978;16(7):533-46.

21. Link CL, McKinlay JB. Disparities in the prevalence of diabetes: is it race/ethnicity or socioeconomic status? Results from the Boston Area Community Health (BACH) survey. Ethn Dis 2009;19(3):288-92.

22. Saydah S, Lochner K. Socioeconomic status and risk of diabetes-related mortality in the U.S. Public Health Rep 2010; 125(3):377-88.

23. National Center for Health Statistics. Healthy people 2000 final review. Hyattsville (MD): Public Health Service; 2001.

24. About healthy people; 2011. http://www.healthypeople.gov/ 2020/default.aspx. Accessed March 11, 2016.

25. Agency for Healthcare Research and Quality. AHRQ activities to reduce racial and ethnic disparities in health care; 2009. http://www.ahrq.gov/sites/default/files/publications/files/ disparities.pdf. Accessed March 11, 2016.

26. Shi L, Starfield B, Politzer R, Regan J. Primary care, self-rated health, and reductions in social disparities in health. Health Serv Res 2002;37(3):529-50.
27. Anderson NB, Bulatao RA, Cohen B, editors. Critical perspectives on racial and ethnic differences in health in late life. Washington (DC): National Academies Press, National Research Council Panel on Race, Ethnicity, and Health in Later Life; 2004. Chapter 9: Race/ethnicity, socioeconomic status, and health. http://www.ncbi.nlm.nih.gov/books/ NBK25526/. Accessed March 11, 2016.

28. US Department of Health and Human Services. HHS action plan to reduce racial and ethnic health disparities; 2011. http:// w w w . minority halth.hhs.gov/n pa/templates/ content.aspx?lvl=1\&lvlid=33\&ID=285. Accessed March 11, 2016.

29. Shi L, Macinko J, Starfield B, Politzer R, Wulu J, Xu J. Primary care, social inequalities and all-cause, heart disease and cancer mortality in US counties: a comparison between urban and non-urban areas. Public Health 2005; 119(8):699-710.

30. Shi L, Macinko J, Starfield B, Wulu J, Regan J, Politzer R. The relationship between primary care, income inequality, and mortality in US States, 1980-1995. J Am Board Fam Pract $2003 ; 16(5): 412-22$.

\footnotetext{
The opinions expressed by authors contributing to this journal do not necessarily reflect the opinions of the U.S. Department of Health and Human Services, the Public Health Service, the Centers for Disease Control and Prevention, or the authors' affiliated institutions.
} 


\section{Tables}

Table 1. Demographic and Primary Care Characteristics for Population With Type 2 Diabetes, Medical Expenditure Panel Survey, 2012

\begin{tabular}{|c|c|c|}
\hline Characteristic & No. $(N=2,617)$ & Weighted No. $(\mathrm{N}=21,813,781)$ (Weighted \%) $[95 \% \mathrm{Cl}]$ \\
\hline \multicolumn{3}{|c|}{ Predisposing Factors } \\
\hline \multicolumn{3}{|l|}{ Age, $y^{a}$} \\
\hline $18-45$ & 403 & $2,924,379$ (13.4) [11.7-15.1] \\
\hline $46-64$ & 1,164 & $9,561,753(43.8)[40.9-46.7]$ \\
\hline$>64$ & 1,049 & $9,325,508(42.8)[39.9-45.7]$ \\
\hline \multicolumn{3}{|l|}{$\operatorname{Sex}^{\mathrm{b}}$} \\
\hline Male & 1,230 & $11,156,923(51.1)[48.7-53.5]$ \\
\hline Female & 1,387 & $10,656,858(48.9)[46.5-51.3]$ \\
\hline \multicolumn{3}{|l|}{ Race/ethnicity ${ }^{a}$} \\
\hline Non-Hispanic white & 953 & $13,159,194(60.3)[57.0-63.6]$ \\
\hline Non-Hispanic black & 683 & $3,368,274(15.4)[13.2-17.6]$ \\
\hline Hispanic & 743 & $3,592,967$ (16.5) [13.8-19.2] \\
\hline Non-Hispanic Asian & 171 & $1,012,791(4.6)[3.5-5.7]$ \\
\hline Non-Hispanic other & 67 & $680,554(3.1)[1.9-4.3]$ \\
\hline \multicolumn{3}{|l|}{ Health insurance ${ }^{a}$} \\
\hline Private & 1,260 & $12,567,988(57.6)[54.7-60.5]$ \\
\hline Public & 1,041 & $7,514,538(34.5)[31.8-37.2]$ \\
\hline No insurance & 316 & $1,731,254$ (7.9) [6.6-9.2] \\
\hline \multicolumn{3}{|l|}{ Education $^{a}$} \\
\hline No degree & 373 & $2,135,699$ (20.9) [18.4-23.4] \\
\hline High school diploma & 655 & $5,823,750(57.0)[53.5-60.5]$ \\
\hline$\geq$ Bachelor degree & 193 & $1,686,156$ (16.5) [14.0-19.0] \\
\hline Other & 63 & $565,057(5.5)$ [3.8-7.2] \\
\hline \multicolumn{3}{|l|}{ Employment status $^{a}$} \\
\hline Not employed & 1,566 & $12,807,108$ (58.9) [56.2-61.6] \\
\hline Employed & 1,046 & $8,952,016$ (41.1) [38.4-43.8] \\
\hline \multicolumn{3}{|l|}{ Annual income, \$ } \\
\hline$<20,000$ & 1,500 & $10,985,633(50.4)[47.7-53.1]$ \\
\hline $20,000-39,999$ & 612 & $5,322,165$ (24.4) [22.4-26.4] \\
\hline$\geq 40,000$ & 504 & $5,493,176(25.2)[22.7-27.7]$ \\
\hline \multicolumn{3}{|l|}{ Marital status $^{a}$} \\
\hline Not married & 1,245 & $9,458,394(43.4)[41.0-45.8]$ \\
\hline Married & 1,372 & $12,355,387$ (56.6) [54.2-59.0] \\
\hline \multicolumn{3}{|c|}{ Enabling Factors } \\
\hline Metropolitan statis & & \\
\hline
\end{tabular}

Abbreviation: ADL, activities of daily living; $\mathrm{Cl}$, confidence interval; IADL, instrumental activities of daily living; USC, usual source of care.

${ }^{\text {a }} P<.001$.

${ }^{\mathrm{b}} P<.01$.

(continued on next page)

The opinions expressed by authors contributing to this journal do not necessarily reflect the opinions of the U.S. Department of Health and Human Services, the Public Health Service, the Centers for Disease Control and Prevention, or the authors' affiliated institutions. 
(continued)

Table 1. Demographic and Primary Care Characteristics for Population With Type 2 Diabetes, Medical Expenditure Panel Survey, 2012

\begin{tabular}{|c|c|c|}
\hline Characteristic & No. $(\mathrm{N}=2,617)$ & Weighted No. $(\mathrm{N}=21,813,781)$ (Weighted \%) $[95 \% \mathrm{Cl}]$ \\
\hline No & 387 & $3,870,681(17.7)[14.6-20.8]$ \\
\hline Yes & 2,229 & $17,940,960(82.3)[79.2-85.4]$ \\
\hline \multicolumn{3}{|l|}{ Census region } \\
\hline Northeast & 424 & $3,855,015$ (17.7) [15.2-20.2] \\
\hline Midwest & 449 & $4,705,831(21.6)[19.1-24.1]$ \\
\hline South & 1,109 & $8,893,429(40.8)[38.1-43.5]$ \\
\hline West & 634 & $4,357,367(20.0)[17.8-22.2]$ \\
\hline \multicolumn{3}{|c|}{ Need Factors } \\
\hline \multicolumn{3}{|l|}{ Perceived health status ${ }^{a}$} \\
\hline Excellent/very good/good & 1,656 & $14,350,075(65.8)[63.4-68.2]$ \\
\hline Fair/poor & 961 & $7,463,705$ (34.2) [31.8-36.6] \\
\hline \multicolumn{3}{|c|}{ Perceived mental health status ${ }^{a}$} \\
\hline Excellent/very good/good & 2,203 & $18,510,339(84.9)[83.1-86.7]$ \\
\hline Fair/poor & 414 & $3,303,441(15.1)[13.3-16.9]$ \\
\hline \multicolumn{3}{|l|}{ Help with $A D L^{a}$} \\
\hline No & 2,457 & $20,608,010(94.5)[93.2-95.8]$ \\
\hline Yes & 160 & $1,205,770(5.5)[4.2-6.8]$ \\
\hline \multicolumn{3}{|l|}{ Help with IADL ${ }^{a}$} \\
\hline No & 2,362 & $19,750,771$ (90.5) [89.1-91.9] \\
\hline Yes & 255 & $2,063,009$ (9.5) [8.1-10.9] \\
\hline \multicolumn{3}{|c|}{ Primary Care Attribute } \\
\hline \multicolumn{3}{|l|}{ First Contact } \\
\hline \multicolumn{3}{|l|}{ Have USC ${ }^{a}$} \\
\hline No & 253 & $1,676,213$ (7.8) [6.3-9.3] \\
\hline Yes & 2,316 & $19,799,721(92.2)[90.7-93.7]$ \\
\hline \multicolumn{3}{|l|}{ Provider type of USC ${ }^{a}$} \\
\hline Facility & 1,140 & $8,879,718$ (44.9) [41.5-48.3] \\
\hline Person/person in facility & 1,176 & $10,920,003$ (55.1) [51.7-58.5] \\
\hline \multicolumn{3}{|l|}{ Provider specialty of USC } \\
\hline Primary care & 1,066 & $9,727,524(89.1)[86.1-92.1]$ \\
\hline Other & 110 & $1,192,479(10.9)[7.9-13.9]$ \\
\hline \multicolumn{3}{|l|}{ USC location } \\
\hline Office & 1,664 & $15,321,478(77.5)[74.7-80.3]$ \\
\hline Hospital & 648 & $4,453,434(22.5)[19.7-25.3]$ \\
\hline \multicolumn{3}{|c|}{ Difficulty in contacting USC by telephone ${ }^{a}$} \\
\hline Not very difficult & 2,096 & $17,845,798$ (93.9) [92.5-95.3] \\
\hline
\end{tabular}

Abbreviation: ADL, activities of daily living; Cl, confidence interval; IADL, instrumental activities of daily living; USC, usual source of care.

a $P<.001$.

${ }^{\mathrm{b}} P<.01$.

(continued on next page)

The opinions expressed by authors contributing to this journal do not necessarily reflect the opinions of the U.S. Department of Health and Human Services, the Public Health Service, the Centers for Disease Control and Prevention, or the authors' affiliated institutions. 
(continued)

Table 1. Demographic and Primary Care Characteristics for Population With Type 2 Diabetes, Medical Expenditure Panel Survey, 2012

\begin{tabular}{|c|c|c|}
\hline Characteristic & No. $(N=2,617)$ & Weighted No. ( $\mathrm{N}=21,813,781)$ (Weighted \%) $[95 \% \mathrm{Cl}]$ \\
\hline Very difficult & 139 & $1,148,599(6.1)[4.7-7.5]$ \\
\hline \multicolumn{3}{|c|}{ USC has office hours nights/weekends ${ }^{a}$} \\
\hline No & 1,412 & $12,252,897$ (68.9) [66.1-71.7] \\
\hline Yes & 670 & $5,528,129(31.1)[28.3-33.9]$ \\
\hline \multicolumn{3}{|c|}{ How long it takes to get to USC ${ }^{a}$} \\
\hline$\leq 30 \min$ & 1,974 & $17,095,937(86.4)[84.5-88.3]$ \\
\hline$>30 \mathrm{~min}$ & 338 & $2,684,740(13.6)[11.7-15.5]$ \\
\hline \multicolumn{3}{|c|}{ How difficult is it to get to USC } \\
\hline Difficult & 2,280 & $19,579,459$ (99.0) [98.5-99.5] \\
\hline Not difficult & 31 & $192,250(1.0)[0.5-1.5]$ \\
\hline \multicolumn{3}{|l|}{ Longitudinality } \\
\hline \multicolumn{3}{|c|}{ USC provider listens } \\
\hline No & 28 & $151,190(0.8)[0.4-1.2]$ \\
\hline Yes & 2,139 & $18,552,573(99.2)[98.8-99.6]$ \\
\hline \multicolumn{3}{|c|}{ Comprehensiveness } \\
\hline \multicolumn{3}{|c|}{ Goes to USC for preventive health care ${ }^{a}$} \\
\hline No & 24 & $155,285(0.8)[0.4-1.2]$ \\
\hline Yes & 2,288 & $19,605,865(99.2)[98.8-99.6]$ \\
\hline \multicolumn{3}{|l|}{ Coordination } \\
\hline \multicolumn{3}{|c|}{ Provider asks about other treatments } \\
\hline No & 379 & $3,188,383(16.6)[14.5-18.7]$ \\
\hline Yes & 1,875 & $16,007,106(83.4)[81.3-85.5]$ \\
\hline \multicolumn{3}{|c|}{ Goes to USC for referrals } \\
\hline No & 35 & 369,907 (1.9) [1.1-2.7] \\
\hline Yes & 2,277 & $19,416,969$ (98.1) [97.3-98.9] \\
\hline
\end{tabular}

Abbreviation: ADL, activities of daily living; $\mathrm{Cl}$, confidence interval; IADL, instrumental activities of daily living; USC, usual source of care.

a $P<.001$.

${ }^{\mathrm{b}} P<.01$.

The opinions expressed by authors contributing to this journal do not necessarily reflect the opinions of the U.S. Department of Health and Human Services, the Public Health Service, the Centers for Disease Control and Prevention, or the authors' affiliated institutions. 
Table 2. Primary Care Characteristics for Population With Type 2 Diabetes, by Race/Ethnicity, Medical Expenditure Panel Survey, 2012

\begin{tabular}{|c|c|c|c|c|c|c|c|c|c|c|c|c|c|c|c|}
\hline \multirow[b]{3}{*}{ Characteristic } & \multicolumn{15}{|c|}{ Race/Ethnicity } \\
\hline & \multicolumn{3}{|c|}{ Non-Hispanic White } & \multicolumn{3}{|c|}{ Non-Hispanic Black } & \multicolumn{3}{|c|}{ Hispanic } & \multicolumn{3}{|c|}{ Non-Hispanic Asian } & \multicolumn{3}{|c|}{ Non-Hispanic Other } \\
\hline & $\mathbf{n}$ & Wt \% & SE & $\mathrm{n}$ & Wt \% & SE & $\mathbf{n}$ & Wt \% & SE & $\mathrm{n}$ & Wt \% & SE & $\mathrm{n}$ & Wt \% & SE \\
\hline \multicolumn{16}{|c|}{ First Contact } \\
\hline \multicolumn{16}{|l|}{ Have USC ${ }^{a}$} \\
\hline No & 55 & 5.86 & 0.96 & 63 & 8.89 & 1.3 & 120 & 13.93 & 1.7 & 11 & 5.59 & 2 & 4 & 11.1 & 7 \\
\hline Yes & 886 & 94.14 & 0.96 & 605 & 91.11 & 1.3 & 610 & 86.07 & 1.7 & 153 & 94.41 & 2 & 62 & 88.9 & 7 \\
\hline \multicolumn{16}{|l|}{ Provider type of USC ${ }^{b}$} \\
\hline Facility & 358 & 39.67 & 2.3 & 302 & 49.1 & 2.9 & 382 & 60.44 & 3 & 64 & 38.39 & 4.6 & 34 & 60.06 & 9 \\
\hline $\begin{array}{l}\text { Person/person in } \\
\text { facility }\end{array}$ & 528 & 60.33 & 2.3 & 303 & 50.9 & 2.9 & 228 & 39.56 & 3 & 89 & 61.61 & 4.6 & 28 & 39.94 & 9 \\
\hline \multicolumn{16}{|c|}{ Provider specialty of USC } \\
\hline Primary care & 469 & 88.11 & 2 & 277 & 91.26 & 2 & 215 & 92.48 & 2.5 & 80 & 89.47 & 4.1 & 25 & 87.12 & 8.5 \\
\hline Other & 59 & 11.89 & 2 & 26 & 8.74 & 2 & 13 & 7.52 & 2.5 & 9 & 10.53 & 4.1 & 3 & 12.88 & 8.5 \\
\hline \multicolumn{16}{|l|}{ USC location $^{\mathrm{b}}$} \\
\hline Office & 725 & 82.96 & 1.9 & 441 & 74.62 & 2.3 & 336 & 57.39 & 3.1 & 117 & 81.79 & 3.5 & 45 & 75.14 & 5.7 \\
\hline Hospital & 160 & 17.04 & 1.9 & 161 & 25.38 & 2.3 & 274 & 42.61 & 3.1 & 36 & 18.21 & 3.5 & 17 & 24.86 & 5.7 \\
\hline \multicolumn{16}{|c|}{ Difficulty in contacting USC by telephone } \\
\hline Not very difficult & 798 & 93.93 & 1.1 & 560 & 96.57 & 0.82 & 545 & 91.17 & 1.9 & 134 & 94.05 & 2.5 & 59 & 95.41 & 3.1 \\
\hline Very difficult & 54 & 6.07 & 1.1 & 22 & 3.43 & 0.82 & 52 & 8.83 & 1.9 & 8 & 5.95 & 2.5 & 3 & 4.59 & 3.1 \\
\hline \multicolumn{16}{|c|}{ USC has office hours nights/weekends } \\
\hline No & 554 & 70.03 & 2 & 380 & 70.02 & 2.4 & 370 & 68.97 & 2.5 & 78 & 58.66 & 5.7 & 30 & 55.22 & 8.1 \\
\hline Yes & 237 & 29.97 & 2 & 170 & 29.98 & 2.4 & 182 & 31.03 & 2.5 & 59 & 41.34 & 5.7 & 22 & 44.78 & 8.1 \\
\hline \multicolumn{16}{|c|}{ How long it takes to get to USC } \\
\hline$\leq 30 \min$ & 769 & 87.67 & 1.3 & 501 & 83.81 & 1.7 & 518 & 84.89 & 1.9 & 135 & 88.13 & 2.9 & 51 & 79.26 & 7.2 \\
\hline$>30 \min$ & 116 & 12.33 & 1.3 & 102 & 16.19 & 1.7 & 91 & 15.11 & 1.9 & 18 & 11.87 & 2.9 & 11 & 20.74 & 7.2 \\
\hline \multicolumn{16}{|c|}{ How difficult is it to get to USC } \\
\hline Difficult & 875 & 99.26 & 0.3 & 594 & 98.43 & 0.63 & 596 & 98.2 & 0.6 & 153 & 100 & 0 & 62 & 100 & 0 \\
\hline Not difficult & 10 & 0.74 & 0.3 & 8 & 1.57 & 0.63 & 13 & 1.8 & 0.6 & $\mathrm{NA}$ & NA & NA & NA & $\mathrm{NA}$ & NA \\
\hline $\begin{array}{l}\text { First contact domain: } \\
\mathrm{n} \text {, mean score, SE }\end{array}$ & 480 & 6.77 & 0.05 & 282 & 6.82 & 0.06 & 219 & 6.74 & 0.07 & 80 & 7.01 & 0.10 & 20 & 6.59 & 0.17 \\
\hline \multicolumn{16}{|c|}{ Longitudinality } \\
\hline \multicolumn{16}{|l|}{ USC provider listens $^{c}$} \\
\hline No & 4 & 0.4 & 0.21 & 9 & 1.52 & 0.58 & 13 & 1.86 & 0.6 & 2 & 1.08 & 0.8 & $\mathrm{NA}$ & NA & NA \\
\hline Yes & 840 & 99.6 & 0.21 & 564 & 98.48 & 0.58 & 555 & 98.14 & 0.6 & 122 & 98.92 & 0.8 & 58 & 100 & 0 \\
\hline \multicolumn{16}{|c|}{ Comprehensiveness } \\
\hline \multicolumn{16}{|c|}{ Goes to USC for preventive health care ${ }^{c}$} \\
\hline No & 5 & 0.51 & 0.25 & 6 & 1.03 & 0.44 & 9 & 1.08 & 0.3 & 2 & 0.81 & 0.59 & 2 & 3.74 & 2.6 \\
\hline
\end{tabular}

Abbreviations: NA, not applicable; SE, standard error; USC, usual source of care; Wt \%, weighted percentage.

${ }^{\text {a }} P<.01$.

${ }^{\mathrm{b}} P<.001$.

${ }^{\mathrm{c}} P<.05$.

(continued on next page)

The opinions expressed by authors contributing to this journal do not necessarily reflect the opinions of the U.S. Department of Health and Human Services, the Public Health Service, the Centers for Disease Control and Prevention, or the authors' affiliated institutions.

10 Centers for Disease Control and Prevention • www.cdc.gov/pcd/issues/2016/16_0113.htm 
(continued)

Table 2. Primary Care Characteristics for Population With Type 2 Diabetes, by Race/Ethnicity, Medical Expenditure Panel Survey, 2012

\begin{tabular}{|c|c|c|c|c|c|c|c|c|c|c|c|c|c|c|c|}
\hline \multirow[b]{3}{*}{ Characteristic } & \multicolumn{15}{|c|}{ Race/Ethnicity } \\
\hline & \multicolumn{3}{|c|}{ Non-Hispanic White } & \multicolumn{3}{|c|}{ Non-Hispanic Black } & \multicolumn{3}{|c|}{ Hispanic } & \multicolumn{3}{|c|}{ Non-Hispanic Asian } & \multicolumn{3}{|c|}{ Non-Hispanic Other } \\
\hline & $\mathrm{n}$ & Wt \% & SE & $\mathrm{n}$ & Wt \% & SE & $\mathrm{n}$ & Wt \% & SE & $\mathrm{n}$ & Wt \% & SE & $\mathrm{n}$ & Wt \% & SE \\
\hline Yes & 879 & 99.49 & 0.25 & 598 & 98.97 & 0.44 & 600 & 98.92 & 0.3 & 151 & 99.19 & 0.59 & 60 & 96.26 & 2.6 \\
\hline \multicolumn{16}{|c|}{ Coordination } \\
\hline \multicolumn{16}{|c|}{ Provider asks about other treatments } \\
\hline No & 136 & 15.54 & 1.6 & 98 & 17.39 & 1.7 & 101 & 16.15 & 2.2 & 31 & 25.51 & 4 & 13 & 22.81 & 7.4 \\
\hline Yes & 722 & 84.46 & 1.6 & 489 & 82.61 & 1.7 & 498 & 83.85 & 2.2 & 118 & 74.49 & 4 & 48 & 77.19 & 7.4 \\
\hline \multicolumn{16}{|c|}{ Goes to USC for referrals ${ }^{a}$} \\
\hline No & 14 & 1.93 & 0.55 & 7 & 1.29 & 0.5 & 9 & 1.29 & 0.5 & 1 & 0.51 & 0.52 & 4 & 8.6 & 5 \\
\hline Yes & 872 & 98.07 & 0.55 & 597 & 98.71 & 0.5 & 598 & 98.71 & 0.5 & 152 & 99.49 & 0.52 & 58 & 91.4 & 5 \\
\hline \multicolumn{16}{|c|}{ Coordination domain $^{\mathrm{C}}$} \\
\hline No & 146 & 16.65 & 0.02 & 109 & 18.27 & 0.02 & 105 & 17.18 & 0.02 & 38 & 25.51 & 0.04 & 19 & 30.78 & 0.07 \\
\hline Yes & 732 & 83.35 & 0.02 & 490 & 81.73 & 0.02 & 504 & 82.82 & 0.02 & 112 & 74.49 & 0.04 & 43 & 69.22 & 0.07 \\
\hline
\end{tabular}

Abbreviations: NA, not applicable; SE, standard error; USC, usual source of care; Wt \%, weighted percentage.

${ }^{a} P<.01$.

${ }^{\mathrm{b}} P<.001$

${ }^{c} P<.05$.

The opinions expressed by authors contributing to this journal do not necessarily reflect the opinions of the U.S. Department of Health and Human Services, the Public Health Service, the Centers for Disease Control and Prevention, or the authors' affiliated institutions. 
Table 3. Regression Models for Cumulative Effect of Different Factors on Racial/Ethnic Differences in Primary Care Characteristics for Population With Diabetes, Medical Expenditure Panel Survey, 2012

\begin{tabular}{|c|c|c|c|c|}
\hline Characteristic & Model 1: Unadjusted & $\begin{array}{l}\text { Model 2: Model } 1+ \\
\text { Predisposing Factors }\end{array}$ & $\begin{array}{l}\text { Model 3: Model } 2 \text { + Enabling } \\
\text { Factors }\end{array}$ & $\begin{array}{c}\text { Model 4: Model } 3+\text { Need } \\
\text { Factors }\end{array}$ \\
\hline \multicolumn{5}{|c|}{ First Contact $\beta(95 \% \mathrm{Cl})$} \\
\hline \multicolumn{5}{|l|}{ Race/ethnicity } \\
\hline Non-Hispanic white & 1 [Reference] & 1 [Reference] & 1 [Reference] & 1 [Reference] \\
\hline Non-Hispanic black & $0.049(-0.069$ to 0.167$)$ & $0.117(-0.004$ to 0.238$)$ & $0.078(-0.046$ to 0.201$)$ & $0.070(-0.054$ to 0.194$)$ \\
\hline Hispanic & $0.011(-0.118$ to 0.141$)$ & $0.046(-0.088$ to 0.181$)$ & $0.027(-0.114$ to 0.168$)$ & $0.025(-0.116$ to 0.167$)$ \\
\hline Non-Hispanic Asian & $0.264^{\mathrm{a}}$ (0.075 to 0.453$)$ & $0.258^{\mathrm{a}}(0.066$ to 0.450$)$ & $0.270^{\mathrm{a}}(0.070$ to 0.469$)$ & $0.269^{a}$ (0.069 to 0.469$)$ \\
\hline Non-Hispanic other & $-0.062(-0.413$ to 0.289$)$ & $-0.089(-0.439$ to 0.260$)$ & $-0.064(-0.412$ to 0.285$)$ & $-0.057(-0.407$ to 0.292$)$ \\
\hline \multicolumn{5}{|l|}{ Predisposing Factors } \\
\hline \multicolumn{5}{|l|}{ Age, $y$} \\
\hline $18-45$ & & 1 [Reference] & 1 [Reference] & 1 [Reference] \\
\hline $46-64$ & & $-0.187^{b}(-0.353$ to -0.022$)$ & $-0.188^{b}(-0.353$ to -0.023$)$ & $-0.182^{b}(-0.347$ to -0.017$)$ \\
\hline$>64$ & & $-0.086(-0.259$ to 0.088$)$ & $-0.079(-0.251$ to 0.094$)$ & $-0.082(-0.255$ to 0.091$)$ \\
\hline \multicolumn{5}{|l|}{ Sex } \\
\hline Male & & 1 [Reference] & 1 [Reference] & 1 [Reference] \\
\hline Female & & $0.058(-0.042$ to 0.159$)$ & $0.056(-0.045$ to 0.156$)$ & $0.053(-0.048$ to 0.153$)$ \\
\hline \multicolumn{5}{|l|}{ Health insurance } \\
\hline Private & & 1 [Reference] & 1 [Reference] & 1 [Reference] \\
\hline Public & & $0.010(-0.113$ to 0.133$)$ & $0.010(-0.112$ to 0.132$)$ & $0.022(-0.101$ to 0.146$)$ \\
\hline No insurance & & $-0.092(-0.320$ to 0.137$)$ & $-0.082(-0.310$ to 0.145$)$ & $-0.090(-0.317$ to 0.138$)$ \\
\hline \multicolumn{5}{|l|}{ Education } \\
\hline No degree & & 1 [Reference] & 1 [Reference] & 1 [Reference] \\
\hline High school diploma & & $0.016(-0.149$ to 0.180$)$ & $0.000(-0.163$ to 0.164$)$ & $0.004(-0.160$ to 0.168$)$ \\
\hline$\geq$ Bachelor degree & & $-0.051(-0.276$ to 0.174$)$ & $-0.079(-0.303$ to 0.145$)$ & $-0.082(-0.306$ to 0.143$)$ \\
\hline Other & & $-0.155(-0.487$ to 0.178$)$ & $-0.150(-0.481$ to 0.181$)$ & $-0.145(-0.477$ to 0.187$)$ \\
\hline \multicolumn{5}{|l|}{ Employment status } \\
\hline Not employed & & 1 [Reference] & 1 [Reference] & 1 [Reference] \\
\hline Employed & & $0.029(-0.107$ to 0.165$)$ & $0.034(-0.101$ to 0.170$)$ & $0.022(-0.116$ to 0.159$)$ \\
\hline \multicolumn{5}{|l|}{ Annual income, \$ } \\
\hline$<20,000$ & & 1 [Reference] & 1 [Reference] & 1 [Reference] \\
\hline $20,000-39,999$ & & $0.138^{\mathrm{b}}(0.007$ to 0.270$)$ & $0.141^{b}$ (0.009 to 0.273$)$ & $0.140^{b}$ (0.007 to 0.273$)$ \\
\hline$\geq 40,000$ & & $0.106(-0.058$ to 0.270$)$ & $0.094(-0.071$ to 0.259$)$ & $0.091(-0.074$ to 0.257$)$ \\
\hline \multicolumn{5}{|l|}{ Marital status } \\
\hline Not married & & 1 [Reference] & 1 [Reference] & 1 [Reference] \\
\hline Married & & $0.203^{\mathrm{C}}(0.098$ to 0.308$)$ & $0.199^{\mathrm{C}}(0.094$ to 0.304$)$ & $0.189^{\mathrm{C}}(0.084$ to 0.295$)$ \\
\hline
\end{tabular}

Abbreviations: ADL, activities of daily living; Cl, confidence interval; IADL, instrumental activities of daily living; NA, not applicable; OR, odds ratio; USC; usual source of care.

${ }^{a} P<.01$

${ }^{\mathrm{b}} P<.05$.

${ }^{\mathrm{c}} P<.001$.

(continued on next page)

The opinions expressed by authors contributing to this journal do not necessarily reflect the opinions of the U.S. Department of Health and Human Services, the Public Health Service, the Centers for Disease Control and Prevention, or the authors' affiliated institutions. 
(continued)

Table 3. Regression Models for Cumulative Effect of Different Factors on Racial/Ethnic Differences in Primary Care Characteristics for Population With Diabetes, Medical Expenditure Panel Survey, 2012

\begin{tabular}{|c|c|c|c|c|}
\hline Characteristic & Model 1: Unadjusted & $\begin{array}{l}\text { Model 2: Model } 1+ \\
\text { Predisposing Factors }\end{array}$ & $\begin{array}{l}\text { Model 3: Model } 2 \text { + Enabling } \\
\text { Factors }\end{array}$ & $\begin{array}{l}\text { Model 4: Model } 3+\text { Need } \\
\text { Factors }\end{array}$ \\
\hline \multicolumn{5}{|l|}{ Enabling Factors } \\
\hline \multicolumn{5}{|c|}{ Metropolitan statistical area } \\
\hline No & & & 1 [Reference] & 1 [Reference] \\
\hline Yes & & & $0.164^{\mathrm{b}}(0.031$ to 0.296$)$ & $0.160^{b}$ (0.028 to 0.293 \\
\hline \multicolumn{5}{|l|}{ Census region } \\
\hline Northeast & & & 1 [Reference] & 1 [Reference] \\
\hline Midwest & & & $-0.169^{b}(-0.333$ to -0.004$)$ & $-0.165(-0.330$ to 0.000 \\
\hline South & & & $-0.085(-0.225$ to 0.055$)$ & $-0.080(-0.221$ to 0.061$)$ \\
\hline West & & & $-0.280^{a}(-0.441$ to -0.120$)$ & $-0.274^{a}(-0.436$ to -0.112$)$ \\
\hline
\end{tabular}

\section{Need Factors}

Perceived health status

Excellent/very good/good

Fair/poor

1 [Reference]

Perceived mental health status

Excellent/very good/good

Fair/poor

Help with ADL

No

Yes

Help with IADL

No

Yes

\section{Race/ethnicity}

Non-Hispanic white

Non-Hispanic black

Hispanic

Non-Hispanic Asian

Non-Hispanic other

Predisposing Factors

Age, $y$

18-45

$46-64$

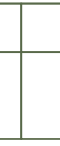

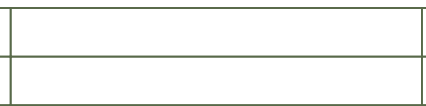

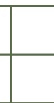

\begin{tabular}{|r|r|}
\hline 1 [Reference] \\
\hline $0.017(-0.102$ to 0.136$)$ \\
\hline
\end{tabular}

1 [Reference]

-0.083 (-0.240 to 0.074$)$

1 [Reference]

$0.054(-0.171$ to 0.280$)$

1 [Reference]

$-0.117(-0.316$ to 0.082$)$

Longitudinality, OR (95\% Cl)

\begin{tabular}{|r|r|r|}
\hline 1 [Reference] & 1 [Reference] & \\
\hline $0.298^{\mathrm{b}}(0.091$ to 0.974$)$ & $0.329(0.098$ to 1.110$)$ & \\
\hline $0.203^{\mathrm{a}}(0.066$ to 0.627$)$ & $0.270^{\mathrm{b}}(0.083$ to 0.883$)$ & $0.343(0.060$ to 1.980$)$ \\
\hline $0.290(0.053$ to 1.603$)$ & $\mathrm{NA}$ & \\
\hline $\mathrm{NA}$ & & 0.06
\end{tabular}

\begin{tabular}{r|}
1 [Reference] \\
$2.323(0.938$ to 5.756$)$
\end{tabular}

1 [Reference]
$2.430(0.977$ to 6.043$)$

1 [Reference]

0.386 (0.112 to 1.332$)$

0.361 (0.107 to 1.224)

0.487 (0.080 to 2.969)

NA

1 [Reference]

0.384 (0.111 to 1.327 )

0.365 (0.107 to 1.245) 0.464 (0.075 to 2.854)

Abbreviations: ADL, activities of daily living; Cl, confidence interval; IADL, instrumental activities of daily living; NA, not applicable; OR, odds ratio; USC; usual source of care.

${ }^{\text {a }} P<.01$.

${ }^{\mathrm{b}} P<.05$.

${ }^{\mathrm{c}} P<.001$.

(continued on next page)

The opinions expressed by authors contributing to this journal do not necessarily reflect the opinions of the U.S. Department of Health and Human Services, the Public Health Service, the Centers for Disease Control and Prevention, or the authors' affiliated institutions. 
(continued)

Table 3. Regression Models for Cumulative Effect of Different Factors on Racial/Ethnic Differences in Primary Care Characteristics for Population With Diabetes, Medical Expenditure Panel Survey, 2012

\begin{tabular}{|c|c|c|c|c|}
\hline Characteristic & Model 1: Unadjusted & $\begin{array}{l}\text { Model 2: Model } 1+ \\
\text { Predisposing Factors }\end{array}$ & $\begin{array}{c}\text { Model 3: Model } 2 \text { + Enabling } \\
\text { Factors }\end{array}$ & $\begin{array}{c}\text { Model 4: Model } 3+\text { Need } \\
\text { Factors }\end{array}$ \\
\hline$>64$ & & $3.267^{b}$ (1.129 to 9.451$)$ & $3.404^{\mathrm{b}}(1.179$ to 9.830$)$ & $3.303^{b}$ (1.134 to 9.618$)$ \\
\hline \multicolumn{5}{|l|}{ Sex } \\
\hline Male & & 1 [Reference] & 1 [Reference] & 1 [Reference] \\
\hline Female & & 2.205 (0.990 to 4.910$)$ & $2.258^{b}$ (1.012 to 5.035$)$ & $2.368^{b}$ (1.059 to 5.295$)$ \\
\hline \multicolumn{5}{|l|}{ Health insurance } \\
\hline Private & & 1 [Reference] & 1 [Reference] & 1 [Reference] \\
\hline Public & & $0.579(0.210$ to 1.598$)$ & $0.615(0.222$ to 1.705$)$ & $0.645(0.231$ to 1.806$)$ \\
\hline No insurance & & $1.141(0.279$ to 4.676$)$ & $1.032(0.251$ to 4.240$)$ & 1.124 (0.270 to 4.684$)$ \\
\hline \multicolumn{5}{|l|}{ Education } \\
\hline No degree & & 1 [Reference] & 1 [Reference] & 1 [Reference] \\
\hline High school diploma & & $0.477(0.117$ to 1.945$)$ & $0.470(0.115$ to 1.928$)$ & $0.464(0.112$ to 1.911$)$ \\
\hline$\geq$ Bachelor degree & & $0.740(0.072$ to 7.625$)$ & $0.772(0.074$ to 8.089$)$ & 0.765 (0.073 to 8.071$)$ \\
\hline Other & & $0.210(0.020$ to 2.244$)$ & 0.221 (0.021 to 2.371$)$ & $0.214(0.020$ to 2.325$)$ \\
\hline \multicolumn{5}{|l|}{ Employment status } \\
\hline Not employed & & 1 [Reference] & 1 [Reference] & 1 [Reference] \\
\hline Employed & & 0.891 (0.320 to 2.477$)$ & $0.840(0.295$ to 2.392$)$ & $0.845(0.290$ to 2.463$)$ \\
\hline \multicolumn{5}{|l|}{ Annual income, \$ } \\
\hline$<20,000$ & & 1 [Reference] & 1 [Reference] & 1 [Reference] \\
\hline $20,000-39,999$ & & $1.632(0.522$ to 5.104$)$ & 1.701 (0.539 to 5.362$)$ & $1.702(0.534$ to 5.420$)$ \\
\hline$\geq 40,000$ & & $3.266(0.602$ to 17.704$)$ & $3.656(0.664$ to 20.134$)$ & 3.621 (0.660 to 19.865$)$ \\
\hline \multicolumn{5}{|l|}{ Marital status } \\
\hline Not married & & 1 [Reference] & 1 [Reference] & 1 [Reference] \\
\hline Married & & $0.655(0.282$ to 1.519$)$ & $0.634(0.271$ to 1.481$)$ & $0.620(0.264$ to 1.458$)$ \\
\hline \multicolumn{5}{|l|}{ Enabling Factors } \\
\hline \multicolumn{5}{|c|}{ Metropolitan statistical area } \\
\hline No & & & 1 [Reference] & 1 [Reference] \\
\hline Yes & & & $0.834(0.237$ to 2.939$)$ & $0.828(0.234$ to 2.925$)$ \\
\hline \multicolumn{5}{|l|}{ Census region } \\
\hline Northeast & & & 1 [Reference] & 1 [Reference] \\
\hline Midwest & & & NA & NA \\
\hline South & & & $1.096(0.370$ to 3.246$)$ & 1.130 (0.379 to 3.371$)$ \\
\hline West & & & $0.890(0.280$ to 2.831$)$ & 0.932 (0.290 to 2.997$)$ \\
\hline
\end{tabular}

\section{Need Factors}

Abbreviations: ADL, activities of daily living; Cl, confidence interval; IADL, instrumental activities of daily living; NA, not applicable; OR, odds ratio; USC; usual source of care.

${ }^{\mathrm{a}} P<.01$.

${ }^{\mathrm{b}} P<.05$.

${ }^{\mathrm{c}} P<.001$.

(continued on next page)

The opinions expressed by authors contributing to this journal do not necessarily reflect the opinions of the U.S. Department of Health and Human Services, the Public Health Service, the Centers for Disease Control and Prevention, or the authors' affiliated institutions. 
(continued)

Table 3. Regression Models for Cumulative Effect of Different Factors on Racial/Ethnic Differences in Primary Care Characteristics for Population With Diabetes, Medical Expenditure Panel Survey, 2012

\begin{tabular}{|c|c|c|c|c|}
\hline Characteristic & Model 1: Unadjusted & $\begin{array}{l}\text { Model 2: Model } 1+ \\
\text { Predisposing Factors }\end{array}$ & $\begin{array}{c}\text { Model 3: Model } 2 \text { + Enabling } \\
\text { Factors }\end{array}$ & $\begin{array}{l}\text { Model 4: Model } 3+\text { Need } \\
\text { Factors }\end{array}$ \\
\hline \multicolumn{5}{|l|}{ Perceived health status } \\
\hline Excellent/very good/good & & & & 1 [Reference] \\
\hline Fair/poor & & & & $0.598(0.260$ to 1.378$)$ \\
\hline \multicolumn{5}{|c|}{ Perceived mental health status } \\
\hline Excellent/very good/good & & & & 1 [Reference] \\
\hline Fair/poor & & & & 2.540 (0.665 to 9.707$)$ \\
\hline \multicolumn{5}{|l|}{ Help with ADL } \\
\hline No & & & & 1 [Reference] \\
\hline Yes & & & & $0.813(0.104$ to 6.336$)$ \\
\hline \multicolumn{5}{|l|}{ Help with IADL } \\
\hline No & & & & 1 [Reference] \\
\hline Yes & & & & $0.929(0.165$ to 5.245$)$ \\
\hline \multicolumn{5}{|c|}{ Comprehensiveness, OR (95\% Cl) } \\
\hline \multicolumn{5}{|l|}{ Race/ethnicity } \\
\hline Non-Hispanic white & 1 [Reference] & 1 [Reference] & 1 [Reference] & 1 [Reference] \\
\hline Non-Hispanic black & $0.567(0.172$ to 1.866$)$ & 0.664 (0.194 to 2.277$)$ & 0.664 (0.187 to 2.363$)$ & $0.688(0.192$ to 2.462$)$ \\
\hline Hispanic & $0.377(0.126$ to 1.131$)$ & $0.468(0.142$ to 1.537$)$ & 0.535 (0.156 to 1.831$)$ & $0.527(0.153$ to 1.822$)$ \\
\hline Non-Hispanic Asian & $0.422(0.081$ to 2.193$)$ & $0.406(0.075$ to 2.196$)$ & 0.504 (0.089 to 2.861$)$ & $0.482(0.084$ to 2.766$)$ \\
\hline Non-Hispanic other & $0.172^{b}$ (0.033 to 0.905$)$ & 0.201 (0.037 to 1.105$)$ & 0.221 (0.040 to 1.230$)$ & 0.209 (0.037 to 1.189$)$ \\
\hline \multicolumn{5}{|l|}{ Predisposing Factors } \\
\hline \multicolumn{5}{|l|}{ Age, y } \\
\hline $18-45$ & & 1 [Reference] & 1 [Reference] & 1 [Reference] \\
\hline $46-64$ & & $2.599(0.847$ to 7.980$)$ & $2.603(0.847$ to 7.998$)$ & 2.594 (0.838 to 8.029$)$ \\
\hline$>64$ & & $1.272(0.389$ to 4.158$)$ & $1.270(0.388$ to 4.156$)$ & 1.262 (0.380 to 4.193$)$ \\
\hline \multicolumn{5}{|l|}{ Sex } \\
\hline Male & & 1 [Reference] & 1 [Reference] & 1 [Reference] \\
\hline Female & & 1.680 (0.718 to 3.929$)$ & $1.732(0.741$ to 4.049$)$ & 1.733 (0.739 to 4.063$)$ \\
\hline \multicolumn{5}{|l|}{ Health insurance } \\
\hline Private & & 1 [Reference] & 1 [Reference] & 1 [Reference] \\
\hline Public & & $0.777(0.257$ to 2.352$)$ & 0.807 (0.266 to 2.448$)$ & 0.802 (0.261 to 2.464$)$ \\
\hline No insurance & & 0.295 (0.080 to 1.092$)$ & 0.281 (0.076 to 1.039$)$ & 0.300 (0.081 to 1.119$)$ \\
\hline \multicolumn{5}{|l|}{ Education } \\
\hline No degree & & 1 [Reference] & 1 [Reference] & 1 [Reference] \\
\hline
\end{tabular}

Abbreviations: ADL, activities of daily living; $\mathrm{Cl}$, confidence interval; IADL, instrumental activities of daily living; NA, not applicable; OR, odds ratio; USC; usual source of care.

${ }^{\text {a }} P<.01$.

${ }^{\mathrm{b}} P<.05$.

${ }^{\mathrm{c}} P<.001$

(continued on next page)

The opinions expressed by authors contributing to this journal do not necessarily reflect the opinions of the U.S. Department of Health and Human Services, the Public Health Service, the Centers for Disease Control and Prevention, or the authors' affiliated institutions. 
(continued)

Table 3. Regression Models for Cumulative Effect of Different Factors on Racial/Ethnic Differences in Primary Care Characteristics for Population With Diabetes, Medical Expenditure Panel Survey, 2012

\begin{tabular}{|c|c|c|c|c|}
\hline Characteristic & Model 1: Unadjusted & $\begin{array}{l}\text { Model 2: Model } 1+ \\
\text { Predisposing Factors }\end{array}$ & $\begin{array}{l}\text { Model 3: Model } 2 \text { + Enabling } \\
\text { Factors }\end{array}$ & $\begin{array}{c}\text { Model 4: Model } 3+\text { Need } \\
\text { Factors }\end{array}$ \\
\hline High school diploma & & $1.761(0.446$ to 6.955$)$ & 1.721 (0.433 to 6.831$)$ & $1.736(0.435$ to 6.926$)$ \\
\hline$\geq$ Bachelor degree & & $0.893(0.151$ to 5.271$)$ & $0.908(0.151$ to 5.446$)$ & 0.897 (0.149 to 5.416$)$ \\
\hline Other & & $0.562(0.058$ to 5.448$)$ & $0.488(0.050$ to 4.748$)$ & 0.489 (0.050 to 4.762$)$ \\
\hline \multicolumn{5}{|l|}{ Employment status } \\
\hline Not employed & & 1 [Reference] & 1 [Reference] & 1 [Reference] \\
\hline Employed & & $0.996(0.331$ to 2.997$)$ & $0.979(0.323$ to 2.971$)$ & 1.097 (0.362 to 3.329$)$ \\
\hline \multicolumn{5}{|l|}{ Annual income, \$ } \\
\hline$<20,000$ & & 1 [Reference] & 1 [Reference] & 1 [Reference] \\
\hline $20,000-39,999$ & & $0.665(0.229$ to 1.931$)$ & $0.664(0.228$ to 1.931$)$ & $0.638(0.217$ to 1.881$)$ \\
\hline$\geq 40,000$ & & $1.135(0.244$ to 5.276$)$ & $1.182(0.252$ to 5.550$)$ & $1.234(0.265$ to 5.746$)$ \\
\hline \multicolumn{5}{|l|}{ Marital status } \\
\hline Not married & & 1 [Reference] & 1 [Reference] & 1 [Reference] \\
\hline Married & & $1.889(0.774$ to 4.612$)$ & $1.864(0.761$ to 4.564$)$ & 1.925 (0.781 to 4.745$)$ \\
\hline
\end{tabular}

Enabling Factors

Metropolitan statistical area

\begin{tabular}{|l|r|r|r|r|}
\hline No & & 1 [Reference] & 1 [Reference] \\
\hline Yes & & & $1.062(0.296$ to 3.816) & $1.055(0.290$ to 3.834) \\
\hline
\end{tabular}

Census region

\begin{tabular}{|l|r|r|r|r|}
\hline Northeast & & & 1 [Reference] & 1 [Reference] \\
\hline Midwest & & & $2.541(0.466$ to 13.846$)$ & $2.498(0.454$ to 13.747$)$ \\
\hline South & & & $1.473(0.467$ to 4.652$)$ & 1.465 (0.460 to 4.669$)$ \\
\hline West & & & 0.991 (0.307 to 3.200$)$ & 1.021 (0.312 to 3.337) \\
\hline
\end{tabular}

Need Factors

Perceived health status

Excellent/very good/good

Fair/poor

1 [Reference]

Perceived mental health status

Excellent/very good/good

Fair/poor

0.909 (0.342 to 2.411$)$

Help with ADL

No

Yes

Help with IADL

1 [Reference]

1.004 (0.253 to 3.983$)$

1 [Reference]

0.226 (0.027 to 1.918)

Abbreviations: ADL, activities of daily living; $\mathrm{Cl}$, confidence interval; IADL, instrumental activities of daily living; NA, not applicable; OR, odds ratio; USC; usual source of care.

${ }^{\text {a }} P<.01$.

${ }^{\mathrm{b}} P<.05$.

${ }^{\mathrm{c}} P<.001$

(continued on next page)

The opinions expressed by authors contributing to this journal do not necessarily reflect the opinions of the U.S. Department of Health and Human Services, the Public Health Service, the Centers for Disease Control and Prevention, or the authors' affiliated institutions. 
(continued)

Table 3. Regression Models for Cumulative Effect of Different Factors on Racial/Ethnic Differences in Primary Care Characteristics for Population With Diabetes, Medical Expenditure Panel Survey, 2012

\begin{tabular}{|l|l|l|c|c|}
\hline Characteristic & Model 1: Unadjusted & $\begin{array}{c}\text { Model 2: Model 1 + } \\
\text { Predisposing Factors }\end{array}$ & $\begin{array}{c}\text { Model 3: Model 2 + Enabling } \\
\text { Factors }\end{array}$ & $\begin{array}{c}\text { Model 4: Model 3 + Need } \\
\text { Factors }\end{array}$ \\
\hline No & & & \\
\hline Yes & & & \\
\hline
\end{tabular}

Coordination, OR $(95 \% \mathrm{Cl})$

\section{Race/ethnicity}

Non-Hispanic white

Non-Hispanic black

Hispanic

Non-Hispanic Asian

Non-Hispanic other

\section{Predisposing Factors}

Age, $y$

18-45

46-64

$>64$

Sex

Male

Female

Health insurance

Private

Public

No insurance

Education

No degree

High school diploma

$\geq$ Bachelor degree

Other

\section{Employment status}

Not employed

Employed

Annual income, \$

$<20,000$

20,000-39,999

$\geq 40,000$

\begin{tabular}{|r|r|}
\hline 1 Reference] & 1 [Reference] \\
\hline $0.990(0.752$ to 1.305$)$ & $1.045(0.786$ to 1.390$)$ \\
\hline $0.941(0.717$ to 1.235$)$ & $1.009(0.751$ to 1.355$)$ \\
\hline $0.785(0.509$ to 1.209$)$ & $0.768(0.494$ to 1.194$)$ \\
\hline $0.600(0.331$ to 1.087$)$ & $0.628(0.345$ to 1.144$)$ \\
\hline
\end{tabular}

1 [Reference]
1 [Reference]

0.954 (0.711 to 1.282 )

1.106 (0.811 to 1.509 )

0.908 (0.574 to 1.437 )

0.678 (0.369 to 1.247$)$ 
(continued)

Table 3. Regression Models for Cumulative Effect of Different Factors on Racial/Ethnic Differences in Primary Care Characteristics for Population With Diabetes, Medical Expenditure Panel Survey, 2012

\begin{tabular}{|c|c|c|c|c|}
\hline Characteristic & Model 1: Unadjusted & $\begin{array}{l}\text { Model 2: Model } 1+ \\
\text { Predisposing Factors }\end{array}$ & $\begin{array}{c}\text { Model 3: Model } 2 \text { + Enabling } \\
\text { Factors }\end{array}$ & $\begin{array}{c}\text { Model 4: Model } 3+\text { Need } \\
\text { Factors }\end{array}$ \\
\hline \multicolumn{5}{|l|}{ Marital status } \\
\hline Not married & & 1 [Reference] & 1 [Reference] & 1 [Reference] \\
\hline Married & & 1.205 (0.956 to 1.519$)$ & 1.216 (0.963 to 1.535$)$ & 1.202 (0.950 to 1.520$)$ \\
\hline \multicolumn{5}{|l|}{ Enabling Factors } \\
\hline \multicolumn{5}{|l|}{ Metropolitan statistical area } \\
\hline No & & & 1 [Reference] & 1 [Reference] \\
\hline Yes & & & $0.638^{\mathrm{b}}(0.451$ to 0.902$)$ & $0.632^{b}$ (0.447 to 0.894$)$ \\
\hline \multicolumn{5}{|l|}{ Census region } \\
\hline Northeast & & & 1 [Reference] & 1 [Reference] \\
\hline Midwest & & & $0.591^{a}(0.403$ to 0.866$)$ & $0.580^{\mathrm{a}}$ (0.396 to 0.851$)$ \\
\hline South & & & 0.955 (0.677 to 1.346$)$ & $0.934(0.662$ to 1.319$)$ \\
\hline West & & & $0.579^{\mathrm{a}}$ (0.405 to 0.827$)$ & $0.560^{\mathrm{a}}$ (0.391 to 0.802$)$ \\
\hline \multicolumn{5}{|l|}{ Need Factors } \\
\hline \multicolumn{5}{|l|}{ Perceived health status } \\
\hline Excellent/very good/good & & & & 1 [Reference] \\
\hline Fair/poor & & & & $1.145(0.874$ to 1.498$)$ \\
\hline \multicolumn{5}{|c|}{ Perceived mental health status } \\
\hline Excellent/very good/good & & & & 1 [Reference] \\
\hline Fair/poor & & & & $0.799(0.565$ to 1.128$)$ \\
\hline \multicolumn{5}{|l|}{ Help with ADL } \\
\hline No & & & & 1 [Reference] \\
\hline Yes & & & & 1.681 (0.907 to 3.114$)$ \\
\hline \multicolumn{5}{|l|}{ Help with IADL } \\
\hline No & & & & 1 [Reference] \\
\hline Yes & & & & 0.942 (0.587 to 1.510$)$ \\
\hline
\end{tabular}

Abbreviations: ADL, activities of daily living; $\mathrm{Cl}$, confidence interval; IADL, instrumental activities of daily living; NA, not applicable; OR, odds ratio; USC; usual source of care.

${ }^{a} P<.01$.

${ }^{\mathrm{b}} P<.05$

${ }^{\mathrm{c}} P<.001$.

The opinions expressed by authors contributing to this journal do not necessarily reflect the opinions of the U.S. Department of Health and Human Services, the Public Health Service, the Centers for Disease Control and Prevention, or the authors' affiliated institutions. 